Original Research Paper

\title{
Structural Performance of Double Laminated Glass Panels with EVA and PVB Interlayer in Four-Point Bending Tests
}

\author{
Tomáš Hána, Martina Eliášová and Zdeněk Sokol \\ Department of Steel and Timber Structures, Faculty of Civil Engineering, \\ Czech Technical University, Prague, Czech Republic
}

\author{
Article history \\ Received: 22-05- 2018 \\ Revised: 12-07-2018 \\ Accepted: 07-08-2018 \\ Corresponding Author: \\ Tomáš Hána, \\ Department of Steel and \\ Timber Structures CTU in \\ Prague, Czech Republic \\ Email: tomas.hana@fsv.cvut.cz
}

\begin{abstract}
Many examples of glass loadbearing structures such as handrails, panes, beams and columns can be found in modern architecture. Most of these elements are made of laminated glass panels. There is a general lack of knowledge about the transfer of shear forces between the glass plies in perpendicularly-loaded laminated panels. This transfer depends significantly on the stiffness of the polymeric interlayer, which is timedependent and temperature-dependent. There are several computational methods for the design of laminated glass that take the shear coupling of the glass plies into account, e.g. analytical methods, numerical modeling and also the draft of European code. These methods need to be verified experimentally. This paper reports on rectangular double-laminated glass panels in a shortterm displacement controlled four-point bending test with an EVA and with a PVB interlayer under a constant temperature. These tests were performed at CTU in Prague. Our experimental results show that panels with an EVA interlayer had greater bending stiffness than panels laminated with PVB and achieved higher ultimate load values. The experimental data were further compared with simplified analytical methods, such as the European draft prEN 16612 and the Enhanced Effective Thickness approach and also a numerical FEM model. Numerical and EET methods results were in good agreement with the experimental data. The way in which the specimens broke was a characteristic feature of laminated glass. The shards remained attached to the interlayer, proving that laminated glass panels can be used safely above the heads of users of the structure. Simplified methods and numerical models validated by experimental tests on perpendicularly-loaded laminated glass panels enable these structures to be designed safely and economically for practical uses.
\end{abstract}

Keywords: Laminated Glass, Tensile Stress, Simplified Approach, Deflections, Comparison, Effective Thickness

\section{Introduction}

Laminated glass as a composition of two or more glass plies bonded together with a polymeric interlayer is a subject of an intensive research (Serafinavičius et al., 2013). The bonding process is usually performed in an autoclave under a pressure of $0.8 \mathrm{MPa}$ and at a temperature of around $140^{\circ} \mathrm{C}$ (O'Regan et al., 2014). The use of laminated glass for loadbearing structures has been increasing, because of its residual loadbearing capacity. In the event of a fracture, the glass fragments adhere to the interlayer. They do not become detached and they are therefore not a threat to users of the building after an accident. Generally, there are no official uniform
European codes that define the design strength of glass with reference to the production process and there are no rules for laminated glass design. Civil engineers must therefore rely on national standards, e.g. German DIN (DIN 18008-1, 2011). At the present time, there are several ways how to design perpendicularly-loaded laminated glass structures when the stiffness of the interlayer is a factor that needs to be taken into consideration. The different ways and methods provide results with a different degree of accuracy and are sometimes not on the safe side. The stiffness of polymeric interlayers is a broader issue, since viscoelastic properties are time- dependent and temperature- dependent. Several types of interlayers can 
be found on the market, but civil engineers do not have access to information about the shear stiffness of most of them. This paper introduces experimental data obtained from four-point bending tests of double laminated glass panels with EVA interlayers and PVB interlayers performed at the Faculty of Civil Engineering of the Czech Technical University in Prague. There is a description of the experimental program, the most important results are presented and a comparison is made between the experimental data from representative specimens, simplified analytical calculation methods and FE numerical simulation. An experimentally verified analytical calculation with satisfactory precision is a good tool for designing laminated glass structures that are economical and also safe.

\section{Materials and Methods}

\section{Experimental Program}

Three types of glass were tested in four-point bending tests: annealed float glass - 10 specimens; heatstrengthened glass - 4 specimens and thermallytoughened glass -5 specimens. Thermallytoughened glass will be referred to in this text as ESG, heatstrengthened glass will be referred to as TVG and annealed float glass will be referred to as FG. Both glass plies in the panel were identical. Nine panels were laminated with EVA interlayers (EVALAM-80-120 ${ }^{\circledR}$ ) and ten panels were laminated with PVB interlayers (Trosifol BG-R-20 ${ }^{\mathbb{R}}$ ) with a nominal thickness of 0.76 $\mathrm{mm}$. The numbers of tested specimens with the appropriate type of interlayer are shown in Table 1. A static scheme of the four-point bending test is shown in Fig. 1. The bending tests were performed in the MTS universal testing machine, with a maximum load capacity of $100 \mathrm{kN}$. The nominal dimensions of the glass panels were $1100 \times 360 \mathrm{~mm}$ and each glass ply was $10 \mathrm{~mm}$ in thickness. A total of 8 LY 11-10/120 strain gauges were attached to the glass surface - 5 strain gauges in compression (upper glass ply) and 3 strain gauges in tension (lower glass ply), as displayed in Fig. 2 and 3. The vertical displacement was measured by displacement sensors I and II placed at the mid-span. Their position is shown in Fig. 4.

\section{Test Set-Up}

The loading was displacement-controlled, with a constant cross-head speed of $1.8 \mathrm{~mm} / \mathrm{min}$, which is in accordance with ČSN EN 1288 (ČSN EN 1288-1, 2001). Each test specimen was loaded in two steps. The first step finished when the lower glass ply broke. The specimen was then unloaded. It was reloaded in the second step to find its residual loadbearing capacity. As soon as the residual loadbearing capacity was reached, the whole laminated panel collapsed. The values of all sensors were offset before each loading step. The measured temperature during the experiments was in the range between $+20^{\circ} \mathrm{C}$ and $+23^{\circ} \mathrm{C}$.
Table 1: Numbers of specimens - glass type and interlayers

\begin{tabular}{lll}
\hline Type of glass/type of interlayer & PVB & EVA \\
\hline Annealed float glass (FG) & 5 & 5 \\
Heat-strengthened glass (TVG) & 2 & 2 \\
Thermally-toughened glass (ESG) & 3 & 2 \\
\hline
\end{tabular}

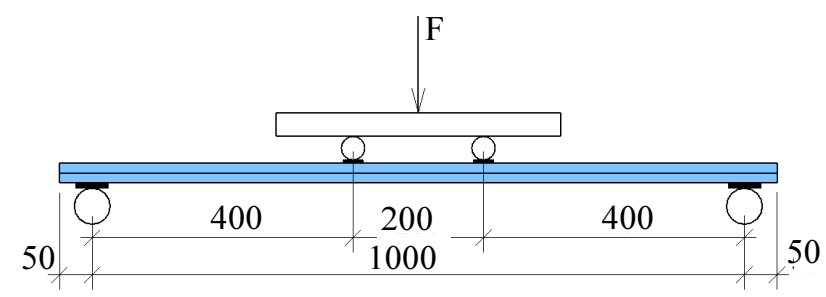

Fig. 1: Static scheme of the four-point bending test

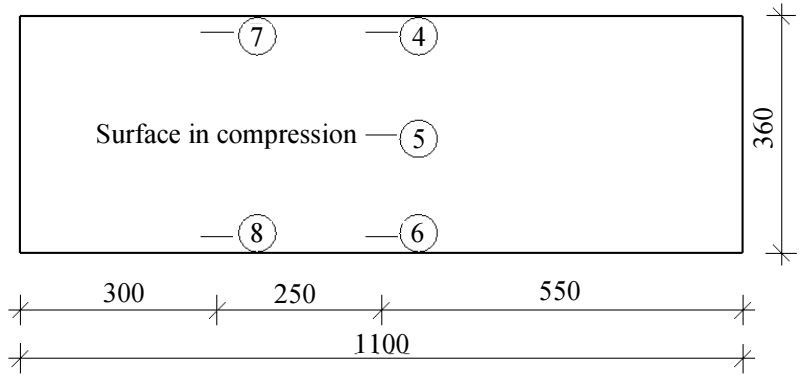

Fig. 2: Position of the strain gauges on the test specimen surface in compression, upper ply

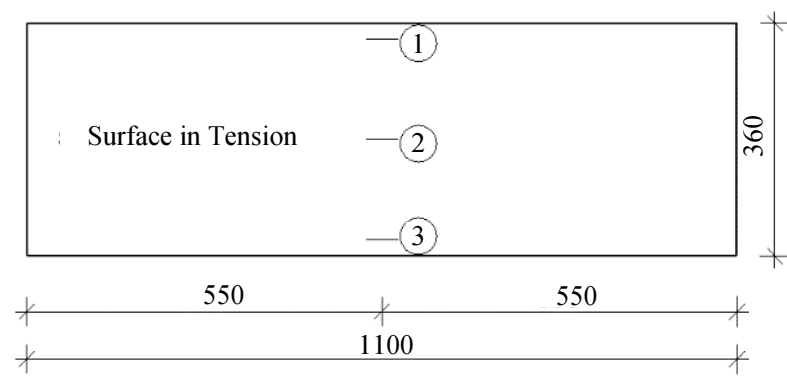

Fig. 3: Position of the strain gauges on the test specimen surface in tension, lower ply

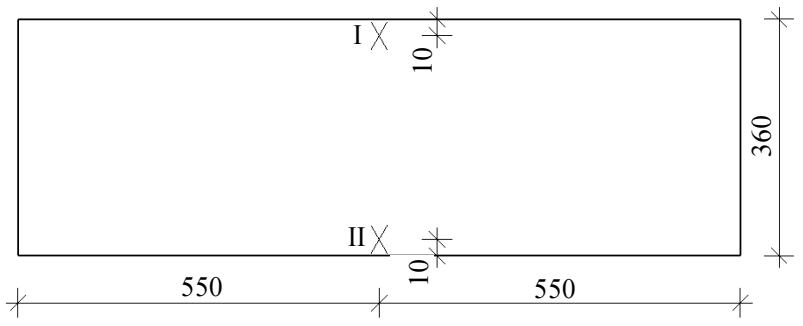

Fig. 4: Position of the displacement sensors on the test specimen 


\section{Analytical Calculation}

The analytical calculation for representative specimens is performed in accordance with the European draft (prEN 16612, 2013) and the Enhanced Effective Thickness method. In the case of (prEN 16612), the laminated panel is converted into a monolithic panel with a so-called effective thickness. This is performed separately for the normal stress and for the deflection calculations of the $j$-th glass ply. This conversion depends on the composition of the laminated package (i.e., on glass and interlayer thickness) and on the stiffness of the interlayer through the transfer coefficient of the shear forces $\omega$. This coefficient can take values from 0 (no shear transfer) to 1 (full shear transfer). A laminated panel with the effective thickness is then assessed. The way in which the $\omega$ coefficient is considered depends on the "stiffness family" of the interlayer, which can be determined according to prEN (prEN 16613, 2013). In this document, the PVB interlayer is classified in "stiffness family" 2. This means it can have $\omega$ values between 0 and 0.3 , depending on the loading case. Further details are given in (prEN 16612, 2013). There is not any "stiffness family" classification for EVA interlayer in (prEN $16613,2013)$. A significant shortcoming of this method lies in the way in which it is simplified, which completely neglects various boundary conditions and the load distribution on a laminated glass panel. This approach has been subjected to criticism (Galuppi and Carfagni, 2013). The effective thickness for deflection and the normal stress calculation of the $j$-th glass ply is determined according to Equation 1 and 2 (prEN 16612, 2013):

$$
h_{e f, w}=\sqrt[3]{\sum_{k} h_{k}^{3}+12 \omega\left(\sum_{i} h_{k} h_{m, k}^{2}\right)},
$$

$$
h_{e f, \sigma, j}=\sqrt{\frac{h_{e f, w}^{3}}{h_{j}+2 \omega h_{m, j}}},
$$

Where:

$\omega \quad=$ The shear transfer coefficient depending on the type of interlayer that is used and loading case (-),

$h_{k}$ and $h_{j} \quad=$ The thicknesses of the individual glass plies $(\mathrm{mm})$

$h_{m, k}$ and $h_{m, j}=$ The distances of the mid-pane of the $k$-th or $j$-th glass plies from the mid-pane of the laminated glass $(\mathrm{mm})$

$h_{e f, \sigma, \mathrm{j}}=$ The effective thickness for normal stress calculation of $j$-th glass ply $(\mathrm{mm})$

$h_{e f, w}=$ The effective thickness for calculating the deflection of any glass ply in the panel (mm)

All symbols that are used are shown in Fig. 5. The Enhanced Effective Thickness approach (EET) is a simple approximate method based on minimizing the strain energy functional and the aim is to find a suitable approximation of the response of the laminated glass beam using appropriate deflection functions (Galuppi et al., 2012). This method is therefore able to take into account a static scheme and the boundary conditions of the laminated glass panel. In addition, it works both for laminated glass beams and panes. Here, too, the deflections and the normal stresses are calculated through the effective thickness, as in the case of prEN (prEN 16612, 2013), but a different approach is used.

Let us consider the double laminated glass beam with the cross section presented in Fig. 6.

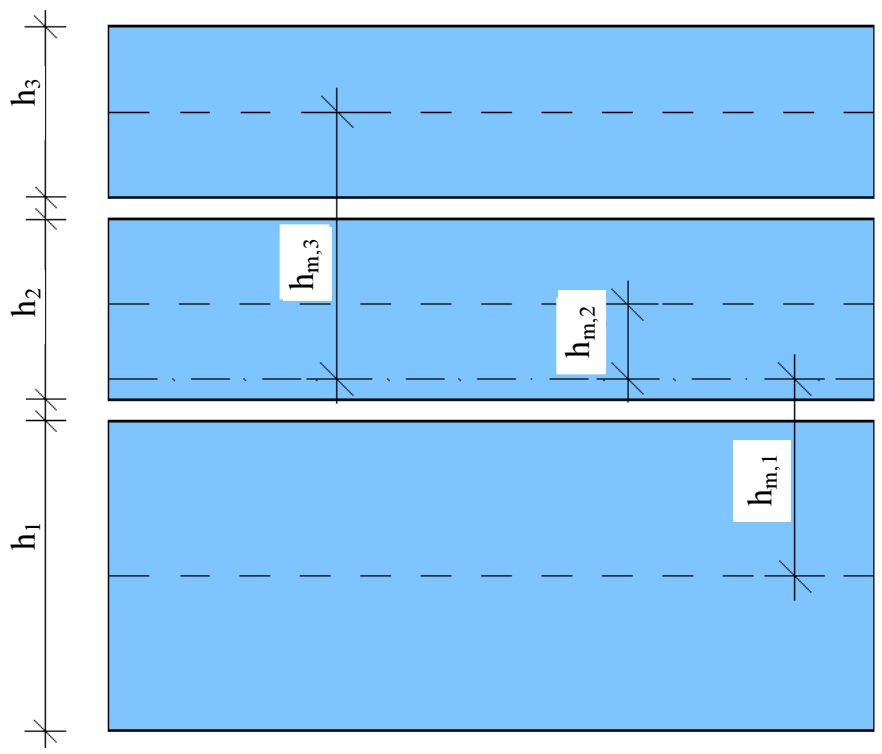

Fig. 5: Important distances for calculating effective thicknesses according to (prEN 16612, 2013) 

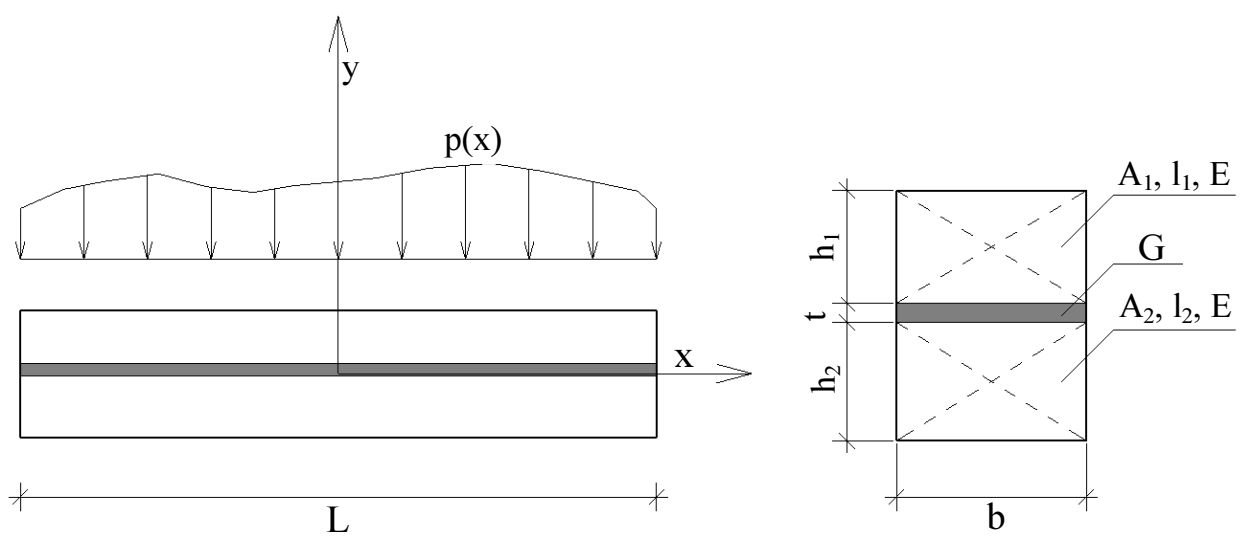

Fig. 6: Input parameters for calculating the stress and deflection of a double laminated glass beam according to EET, general scheme

Then the effective thickness of the deflection $h_{e f, w}$ is calculated according to Equation 3 (Galuppi et al., 2012):

$$
h_{e f, w}=\frac{1}{\sqrt[3]{\frac{\eta}{h_{1}^{3}+h_{2}^{3}+12 I_{S}}+\frac{1-\eta}{h_{1}^{3}+h_{2}^{3}}}}
$$

Where:

$h_{1}$ and $h_{2}=$ The thicknesses of the glass plies (mm)

$I_{s} \quad=$ The "bonding inertia" $\left(\mathrm{mm}^{3}\right)$

$\eta \quad=$ The shear forces transfer factor depending on the shear stiffness of the interlayer, loading and boundary conditions, e.g. the static scheme or the type of load (-) through a non dimensional coefficient $\psi$

The normal stress effective thickness for the individual plies $h_{e f, \sigma}$ is calculated on the basis of Equation 4 (Galuppi et al., 2012):

$$
\begin{aligned}
& h_{1, e f, \sigma}=\frac{1}{\sqrt[3]{\frac{2 \eta h_{s, 2}}{h_{1}^{3}+h_{2}^{3}+12 I_{S}}+\frac{h_{1}}{h_{w}^{3}}}}, \\
& h_{2, e f, \sigma}=\frac{1}{\sqrt{\frac{2 \eta h_{s, 1}}{h_{1}^{3}+h_{2}^{3}+12 I_{S}}+\frac{h_{2}}{h_{w}^{3}}}}
\end{aligned}
$$

where, $h_{s, 1}$ and $h_{s, 2}$ are modified dimensions of the cross section. The other variables were explained in Equation 3.

The stress and deflection effective thickness relations in Equation 3 and 4 are valid for double laminated glass beams with various boundary conditions and for various types of load. Recently, the EET method has been extended to the case of multilayered laminated glass beams composed by three glass plies of an arbitrary thickness, or by an arbitrary number of equally thick glass plies. The formulas for the effective thickness of the deflection $h_{e f, w}$ and the normal stress $h_{i, e f, \sigma}$ for both cases can be found in (Galuppi and Royer-Carfagni, 2014). The experimental results for double laminated glass panels will be in this text compared with the EET thickness approach on the basis of the above equations determined for double laminated glass beams. This is because the experimental static scheme coincides more with the performance of the beam than with the performance of the plate. Nondimensional coefficient $\psi$ through which the shear forces factor $\eta$ was determined, is not tabulated in (Galuppi et al., 2012) for the fourpoint bending static schema. Three-point bending schema was thus considered for $\psi$ evaluation, since it is close to the tested situation. A detailed explanation of the EET variational method approach and the values of shear forces transfer factor $\eta$ for typical boundary conditions and types of load for double laminated glass beams and plates are presented in (Galuppi et al., 2012). The EET method is not the only approximate method that has been used for perpendicularly-loaded laminated glass panels. There are several other methods with various degrees of accuracy, e.g., the Wölfel-Bennison approach and the Newmark approach, the full viscoelastic solution, etc. These can be found in detail in (Galuppi and RoyerCarfagni, 2012). The material properties of the interlayer and of the glass for the analytical calculation according to EET in this text are the same as those used in the FEM numerical calculation.

\section{Numerical Calculation}

The Finite Element Model is a suitable tool for analysing structural elements made of different materials. 3D finite element model in RFEM 4-RF Glass module software was created. This model is based on solid 8-node quadratic bricks, with 2 bricks along the thickness of the glass ply and one brick along the thickness of the interlayer. In the model, the thickness of the interlayer was set as $1 \mathrm{~mm}$ and the thickness of one glass ply was set as $10 \mathrm{~mm}$. A sensitivity study of the meshing, with mesh steps from $50 \mathrm{~mm}$ to $10 \mathrm{~mm}$ with a step of $10 \mathrm{~mm}$ for the ultimate load, was performed for 
one case of PVB and for one EVA specimen. The differences in stress and in deflection between the borderline cases were up to $1,3 \%$. A basic mesh step of $20 \mathrm{~mm}$ was finally considered in the model. The structured mesh was therefore created by dividing the span of the beam into 50 elements and dividing the width into 18 elements. The meshing density along the thickness of the glass panel and the interlayer in RFEM is the default setting. It cannot be modified, since this software was developed for quick engineering calculations of laminated glass structures. The width/height ratio of the interlayer element was 20 in order to avoid such shear locking (Molnár et al., 2012). A part of the adopted mesh of the FEM model is displayed in Fig. 7. All numerical calculations were performed by 1 st order analysis, assuming small strains. It was necessary to provide suitable model input values that would provide reliable results. A suitable value for the stiffness modulus of the interlayer was especially important. The glass properties were taken from (prEN $16612,2013)$ and the shear moduli of the interlayer corresponding to the appropriate shear rate values were found in (Hána et al., 2017). Widely-used interlayer materials are generally isotropic with a relation between the $E$ and $G$ moduli through the Poisson coefficient (prEN 16613, 2013). Since the normal stiffness of the interlayer is not of importance, the experimentally verified shear stiffness coefficient is a satisfactory input.

The mechanical characteristics of all materials were considered in the numerical model, as follows:

Glass: $E=70 \mathrm{GPa}, v=0.23$,

PVB: $G=0.8 \mathrm{MPa}, v=0.45$,

EVA: $G=2.4 \mathrm{MPa}, v=0.45$

Figure 8 shows the deformed shape of the representative thermally toughened glass panel laminated with an EVA interlayer under the maximum load of 9.7 $\mathrm{kN}$. The maximum vertical deflection of $17.8 \mathrm{~mm}$ does not exceed the thickness of the panel, so a 1st order calculation is relevant (Serafinavičius et al., 2013).

\section{Results}

Normal Stress Distribution at the Mid-Span Cross Section - 1st Loading Phase

The graph in Fig. 9 shows the normal stress distribution along the mid-span cross section for test specimen ESG-PVB-01. Considering that the panel is symmetrical and symmetrically loaded and taking the Navier bending hypothesis of fully shear coupled plies into account, the normal stress should be symmetrically distributed along the thickness of the cross section and should be uniformly distributed along the width of the cross section. However, the chart in Fig. 9 indicates something slightly different. The normal stress is nonuniformly distributed along the cross section. For wide beams, the Poisson effect generates non-negligible normal stresses in the longitudinal direction, which means that they cannot be uniformly distributed along the width of the cross section, ČSN EN (1288-1).

Experimentally measured values of average ultimate failure forces and average normal stresses at the midspan cross section for lower glass ply breakage for all types of glass and for both interlayers are shown in Table 2. For PVB, the differences in the normal stress between strain gauges placed opposite to each other along the thickness of the cross section increase as the load increases. This indicates that PVB exhibits non-negligible shear deformation and is therefore not able to provide full shear coupling of the glass plies, especially for higher values of the acting force. In case of EVA, these differences are less pronounced.

Table 2 also shows that panels of the same type of glass laminated with EVA attain higher average ultimate load values than panels laminated with PVB. The normal stress was calculated from the measured strains, assuming Young's glass modulus $E=70 \mathrm{GPa}$ (DIN 18008-1, 2011). The standard deviations of the experimental values are shown in Table 3. In the case of only two specific glassinterlayer specimens tested here, see Table 1, this statistic is not relevant thus standard deviations of their measured values are not included in Table 3 .
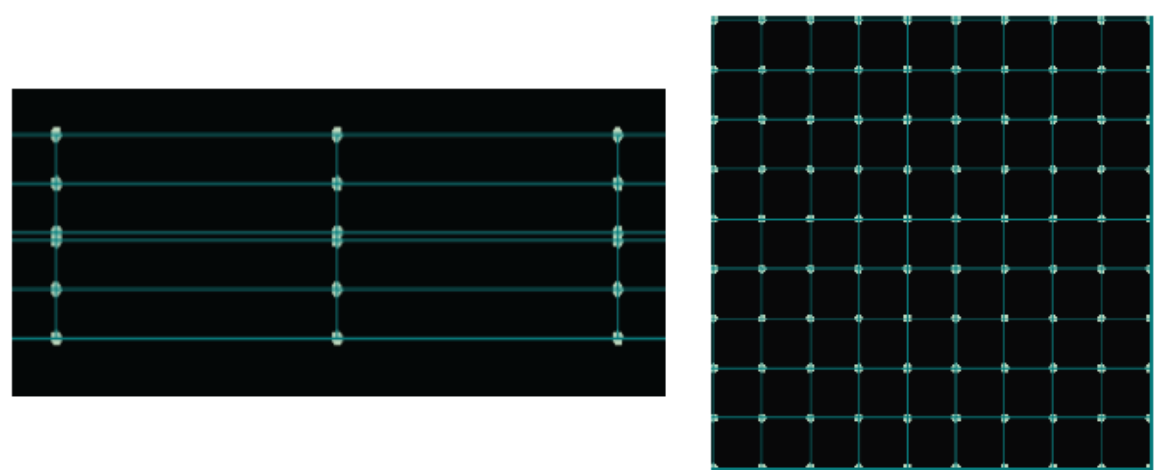

Fig. 7: Part of the mesh along the panel thickness (left) and in plane of the panel (right) used in the numerical simulations 


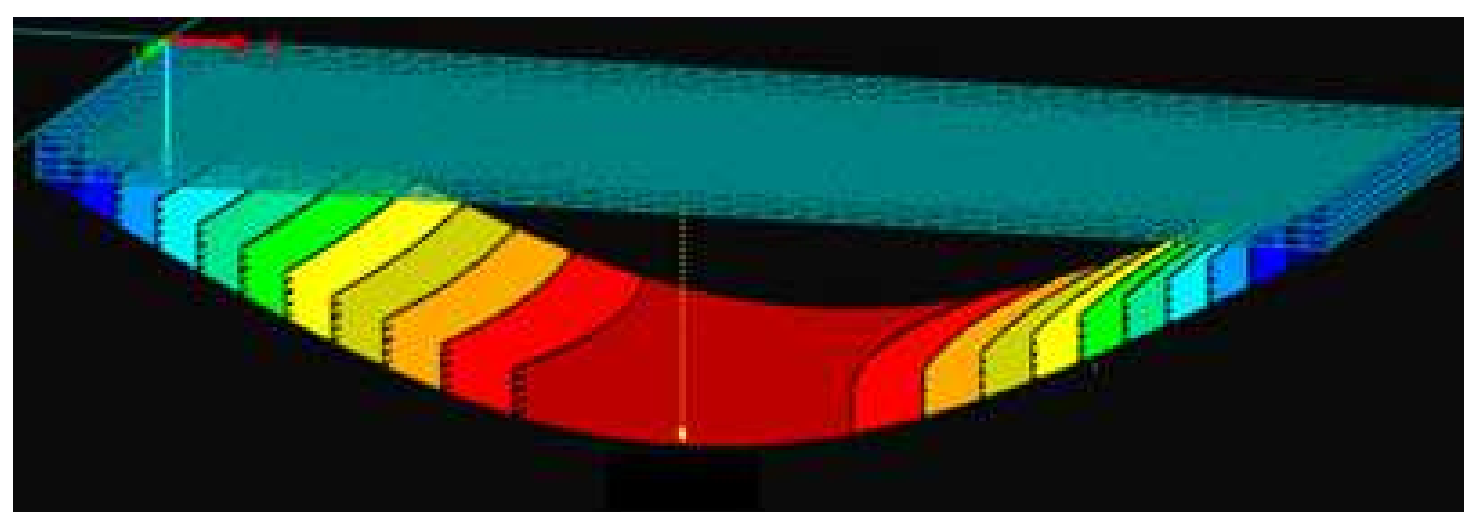

Fig. 8: Deformed shape of a double laminated glass panel with EVA under the maximum bending load, FEM model

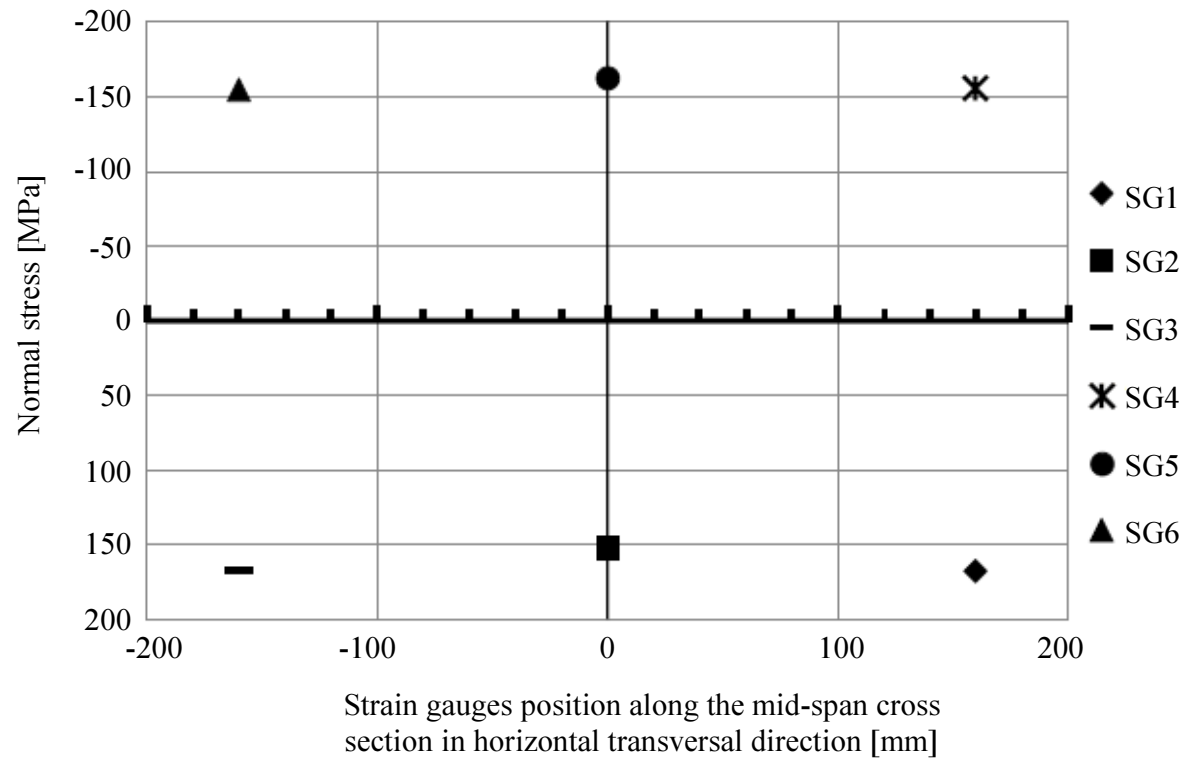

Fig. 9: Normal stress distribution along the mid-span cross section of test specimen ESG-PVB-01

Table 2: Average ultimate failure forces and average normal stresses in the mid-span cross section for lower glass ply breakage obtained from all tested specimens

\begin{tabular}{|c|c|c|c|c|c|c|c|}
\hline Specimen & $\begin{array}{l}\text { Force } \\
\text { F kN }\end{array}$ & $\begin{array}{l}\text { Stress } \\
\text { SG1 MPa }\end{array}$ & $\begin{array}{l}\text { Stress } \\
\text { SG2 MPa }\end{array}$ & $\begin{array}{l}\text { Stress } \\
\text { SG } 3 \mathrm{MPa}\end{array}$ & $\begin{array}{l}\text { Stress } \\
\mathrm{SG} 4 \mathrm{MPa}\end{array}$ & $\begin{array}{l}\text { Stress } \\
\mathrm{SG} 5 \mathrm{MPa}\end{array}$ & $\begin{array}{l}\text { Stress } \\
\text { SG } 6 \mathrm{MPa}\end{array}$ \\
\hline ESG-EVA & 16.9 & 147.9 & 118.6 & 143.1 & -136.8 & -154.0 & -149.0 \\
\hline TVG-EVA & 9.4 & 88.2 & 85.9 & 87.3 & -88.2 & -87.3 & -87.4 \\
\hline FG-EVA & 5.5 & 50.5 & 48.8 & 50.0 & -49.8 & -48.7 & -49.2 \\
\hline ESG-PVB & 12.8 & 162.3 & 147.5 & 160.2 & -149.9 & -156.0 & -147.0 \\
\hline TVG-PVB & 7.4 & 94.0 & 87.5 & 94.8 & -89.1 & -89.8 & -88.8 \\
\hline FG-PVB & 4.0 & 43.5 & 46.8 & 43.1 & -48.8 & -47.9 & -47.4 \\
\hline
\end{tabular}

Table 3: Standard deviations of the ultimate failure forces and the normal stresses in the mid-span cross section at the lower glass

\begin{tabular}{|c|c|c|c|c|c|c|c|}
\hline Specimen & $\begin{array}{l}\mathrm{F} \\
\sqrt{ } \text { Var }\end{array}$ & $\begin{array}{l}\text { SG1 } \\
\sqrt{ } \text { Var }\end{array}$ & $\begin{array}{l}\text { SG2 } \\
\sqrt{ } \text { Var }\end{array}$ & $\begin{array}{l}\text { SG3 } \\
\sqrt{ } \text { Var }\end{array}$ & $\begin{array}{l}\text { SG4 } \\
\sqrt{ } \text { Var }\end{array}$ & $\begin{array}{l}\text { SG5 } \\
\sqrt{ } \text { Var }\end{array}$ & $\begin{array}{l}\text { SG6 } \\
\sqrt{\text { Var }}\end{array}$ \\
\hline FG-EVA & 1.10 & 9.94 & 9.55 & 10.12 & 9.82 & 9.63 & 9.77 \\
\hline ESG-PVB & 0.34 & 5.30 & 4.39 & 5.74 & 4.65 & 6.45 & 5.39 \\
\hline FG-PVB & 1.15 & 9.81 & 13.82 & 10.22 & 14.46 & 14.77 & 14.23 \\
\hline
\end{tabular}




\section{A Comparison between the Experimental Data and the Analytical Data - 1st Loading Phase}

The experimental results and also FEM numerical and analytical calculations for representative specimens will be discussed and compared in detail in the following paragraphs. The decisive strain gauges measuring the highest normal stress and the average values of deflection measured by displacement sensors I and II are taken into consideration in the experimental results. All stress and deflection analytical calculations with the appropriate stress and deflection effective thicknesses respect the Navier bending hypothesis. Figures 10 and 11 show this comparison for test specimen ESG-PVB01. According to prEN (prEN 16613, 2013), the PVB interlayer belongs to stiffness family 2 . This stiffness family is categorized in prEN (prEN 16612, 2013) with shear transfer coefficient $\omega$ values of 0 to 0.3 , depending on the loading case. An analytical calculation with effective thicknesses corresponding to these $\omega$ values was therefore performed for the sake of comparison. The graphs in Fig. 10 and 11 indicate that the experimental values lie between those recommended in (prEN 16612, 2013). If we were to take $\omega=0$, which is recommended for most cases, the analytical calculation would be too conservative.

A comparison of the numerical approach and the EET approach shows that both of them are close to the experimental values, but that they are not on the safe side. It can be seen, however, that the PVB shear stiffness input value was satisfactory. For a comparison of the approaches, the values of the normal stress, the average vertical deflection and the bending stiffness for the acting force of $12 \mathrm{kN}$ for the ESG-PVB-01 specimen are shown in Table 4. When taking $\omega=0$, the obtained normal stress almost $200 \mathrm{MPa}$ would be far from the experiment. The best accordance with the experiment would be assured by numerical approach. The same applies to vertical deflections.

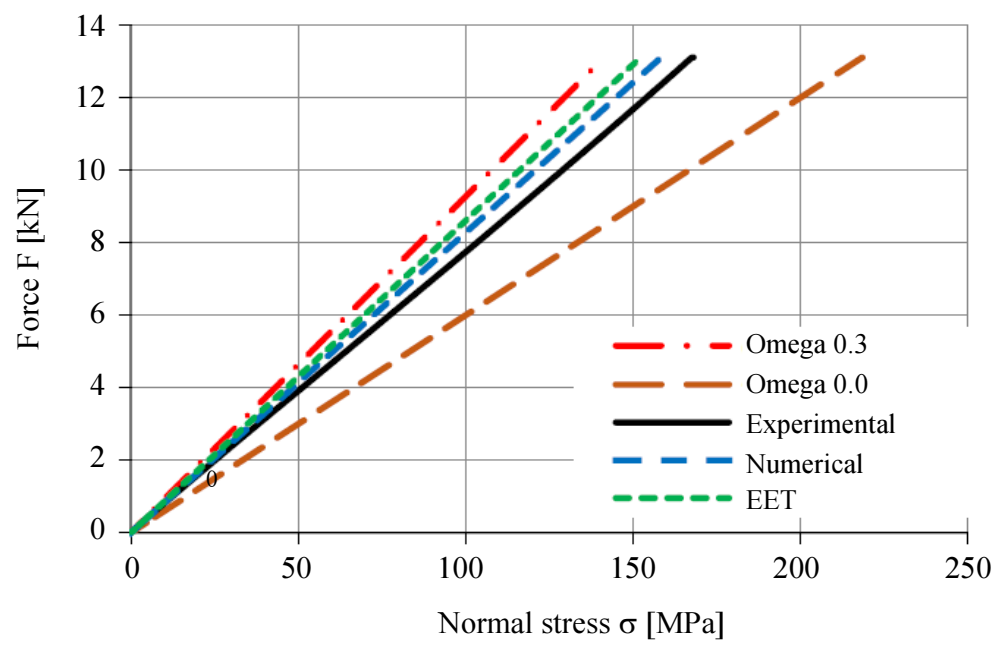

Fig. 10: Force-Stress relations for different prediction methods, test specimen ESG-PVB-01

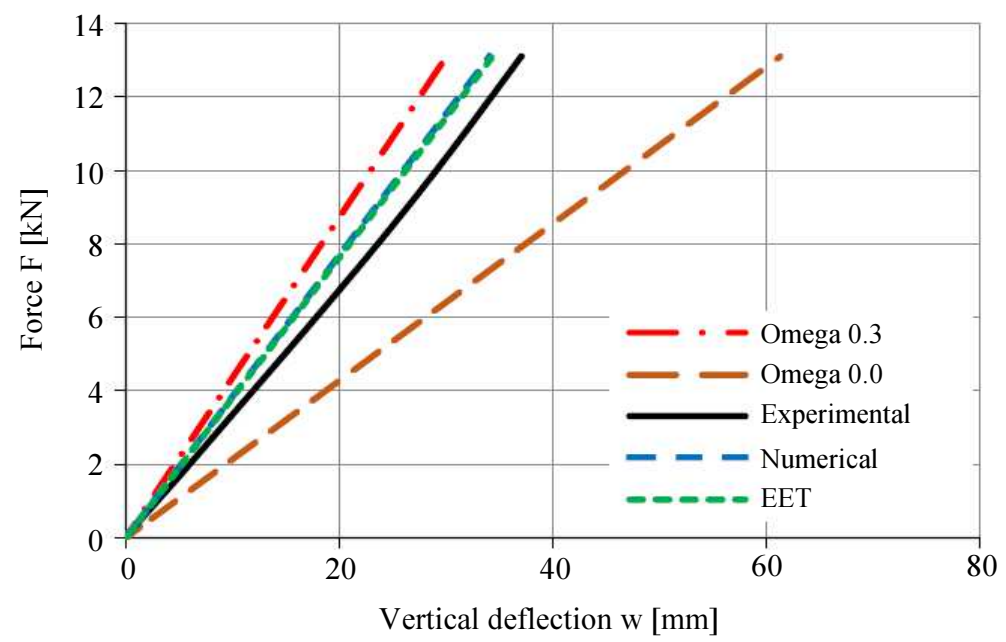

Fig. 11: Force-Deflection relations for different prediction methods, test specimen ESG-PVB-01 
There were similar relations for two other ESG-PVB test specimens. Fig. 12 and Fig. 13 compare the analytical results and the numerical results with the experimental data for test specimen ESG-EVA-04. PrEN 16613 provides no recommended value for EVA shear transfer coefficient $\omega$. In this text, it is therefore assumed that EVA has values of 0 and 0.3 for this coefficient, as in the case of PVB, for the sake of comparison. The chart in Fig. 12 shows that the experimental force-stress relation for EVA does not lie within the range of shear coefficient 0 and 0.3 . This indicates that EVA exhibits a stiffer shear response and should be given a higher $\omega$ coefficient. The numerical approach and the EET approach cover the experimental data with satisfactory precision. The situation is similar in the case of deflections, see Fig. 13. The experimental deflections are lower than those found by analytical methods, but they are sufficiently close to EET and the numerical approach, which give the identical results. For normal stresses and deflections, prEN 16612 would provide excessively conservative results when taking shear transfer coefficient $\omega=0$. The relations were similar for other ESG-EVA test specimen. Table 5 presents an example of the values that were obtained, the normal stress, the average vertical deflection and the bending stiffness for the acting force of $15 \mathrm{kN}$ of the specimen ESG-EVA-04. The difference of normal stress calculated according to prEN 16612 with $\omega=0.3$ and experiment is $20.7 \mathrm{MPa}$. If the normal stress were calculated according to EET, this difference would be much lower, only $2.5 \mathrm{MPa}$. The differences of the deflections are in a similar manner.
Figure 14 and 15 present an analytical and numerical comparison with the experimental data for test specimen FG-PVB-07. The experimental behaviour and the analytical behaviour are similar as for ESG specimens laminated with an PVB interlayer. The experimentally observed relationships also lie between the analytically calculated relationships according to prEN (prEN 16612, 2013 ) in the case of float glass. However, the values are closer to $\omega=0.3$, which is recommended in (prEN 16612 , 2013) only for a wind load. This does not correlate with the loading rate used in the experiment. Taking $\omega=0$, which is preferred in (prEN 16612, 2013) for most loading cases, would lead to excessively conservative results. The numerical and EET approaches correlate well with the experimental data for stress and also for deflections. This confirms that the PVB interlayer stiffness value taken from (Hána et al., 2017) is appropriate. The relations presented in Fig. 14 and 15 are similar to the relations for the other FG-PVB specimens. The values obtained for specimen FG-PVB07 loaded by $2 \mathrm{kN}$ are presented Table 6 for a comparison of the methods. When taking $\omega=0$, one obtains the value of normal stress $33.3 \mathrm{MPa}$. When the value $\omega=0.3$ is considered, obtained normal stress is only $21.6 \mathrm{MPa}$. This is more realistic, since the experimental normal stress value for $2 \mathrm{kN}$ was meaured as 24.1 MPa. The values of normal stresses correlate with the values of bending stiffness, since the experimental bending stiffness $0.35 \mathrm{kN} / \mathrm{mm}$ lies between 0.21 and 0.44 $\mathrm{kN} / \mathrm{mm}$ calculated according to prEN 16612.

Table 4: Values of normal stress, average deflections and bending stiffness for force $12 \mathrm{kN}$, specimen ESG-PVB-01

\begin{tabular}{llll}
\hline Method & Stress (SG1) Mpa & Deflection $\mathrm{mm}$ & Stiffness $\mathrm{kN} / \mathrm{mm}$ \\
\hline Experiment & 154.1 & 34.2 & 0.35 \\
prEN16612 $(\omega=0)$ & 199.9 & 56.1 & 0.21 \\
prEN 16612 $(\omega=0.3)$ & 129.5 & 27.5 & 0.44 \\
Numerical results & 145.2 & 31.2 & 0.38 \\
EET & 139.3 & 31.4 & 0.38 \\
\hline
\end{tabular}

Table 5: Values of the normal stress, the average deflections and the bending stiffness for a force of $15 \mathrm{kN}$, specimen ESG-EVA-04

\begin{tabular}{llll}
\hline Method & Stress (SG1) Mpa & Deflection mm & Stiffness $\mathrm{kN} / \mathrm{mm}$ \\
\hline Experiment & 141.2 & 25.5 & 0.59 \\
prEN $16612(\omega=0)$ & 249.9 & 70.2 & 0.21 \\
prEN16612 $(\omega=0.3)$ & 161.9 & 34.4 & 0.44 \\
Numerical results & 150.0 & 27.0 & 0.56 \\
EET & 143.7 & 26.9 & 0.56 \\
\hline
\end{tabular}

Table 6: Normal stress, average deflection and bending stiffness values for a force of $2 \mathrm{kN}$, specimen FG-PVB-07

\begin{tabular}{llll}
\hline Method & Stress (SG1) Mpa & Deflection $\mathrm{mm}$ & Stiffness $\mathrm{kN} / \mathrm{mm}$ \\
\hline Experiment & 24.1 & 5.6 & 0.35 \\
prEN 16612 $(\omega=0)$ & 33.3 & 9.3 & 0.21 \\
prEN 16612 $(\omega=0.3)$ & 21.6 & 4.5 & 0.44 \\
Numerical results & 24.2 & 5.2 & 0.38 \\
EET & 23.2 & 5.2 & 0.38 \\
\hline
\end{tabular}




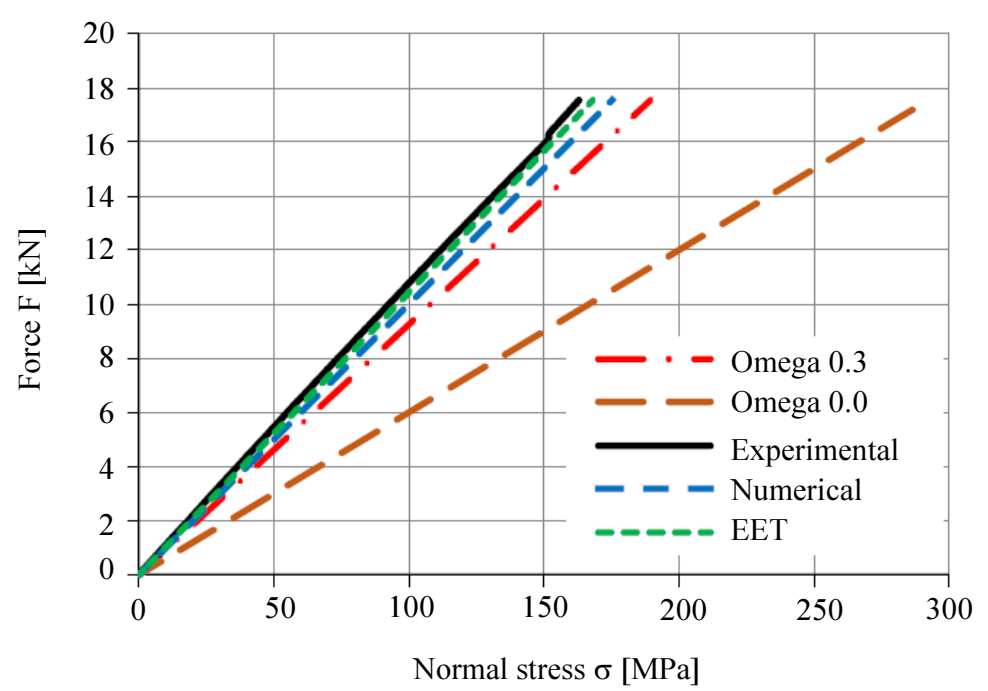

Fig. 12: Force-Stress relations for different prediction methods, test specimen ESG-EVA-04

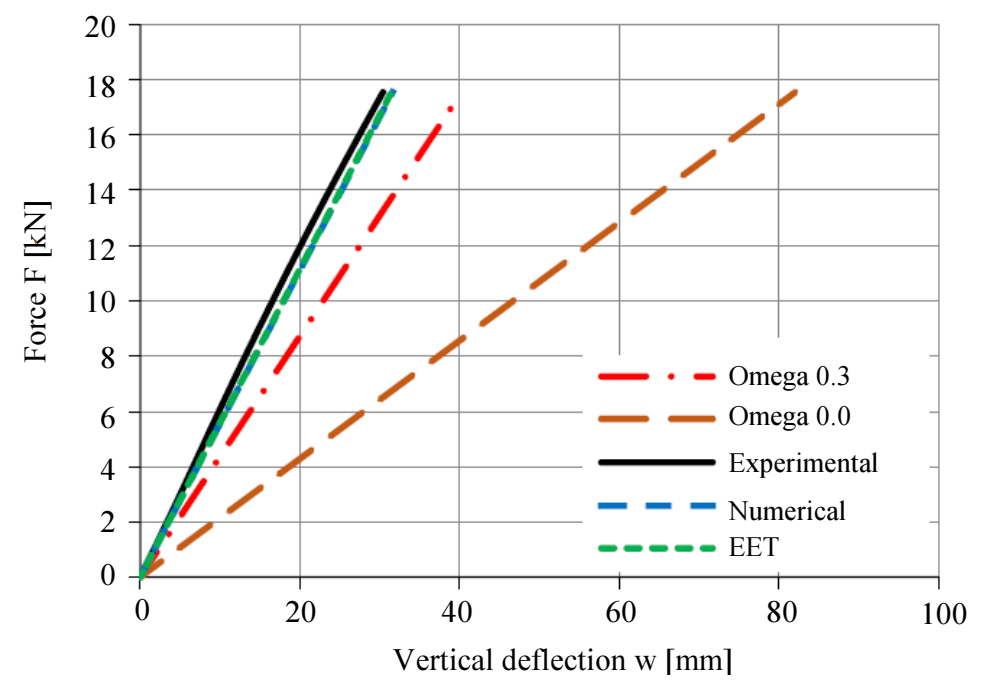

Fig. 13: Force-Deflection relations for different prediction methods, test specimen ESG-EVA-04

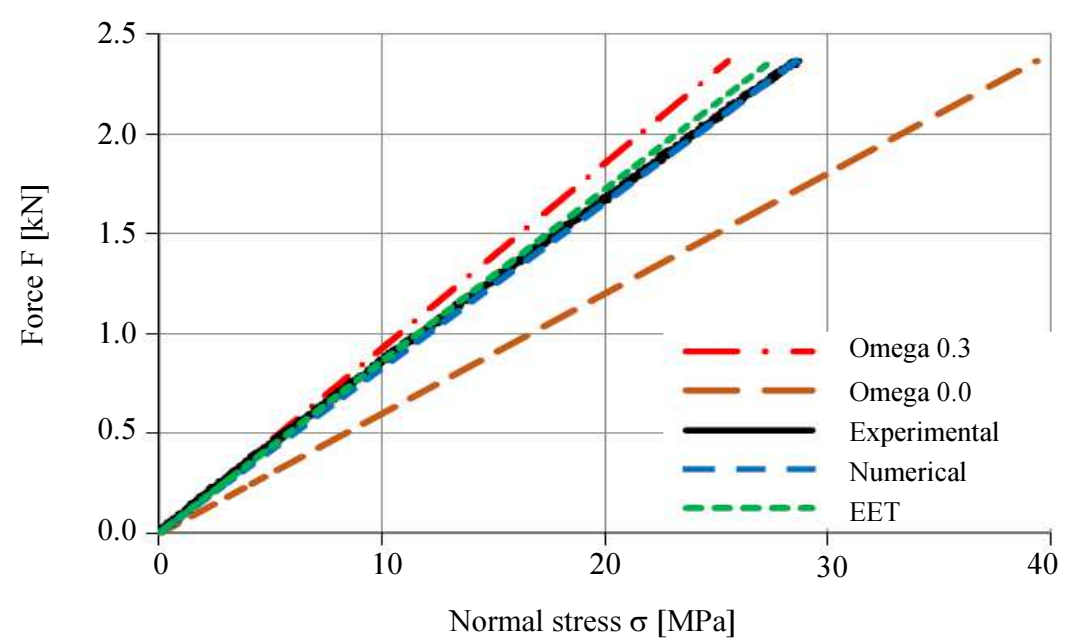

Fig. 14: Force-Stress relations for various prediction methods, test specimen FG-PVB-07 


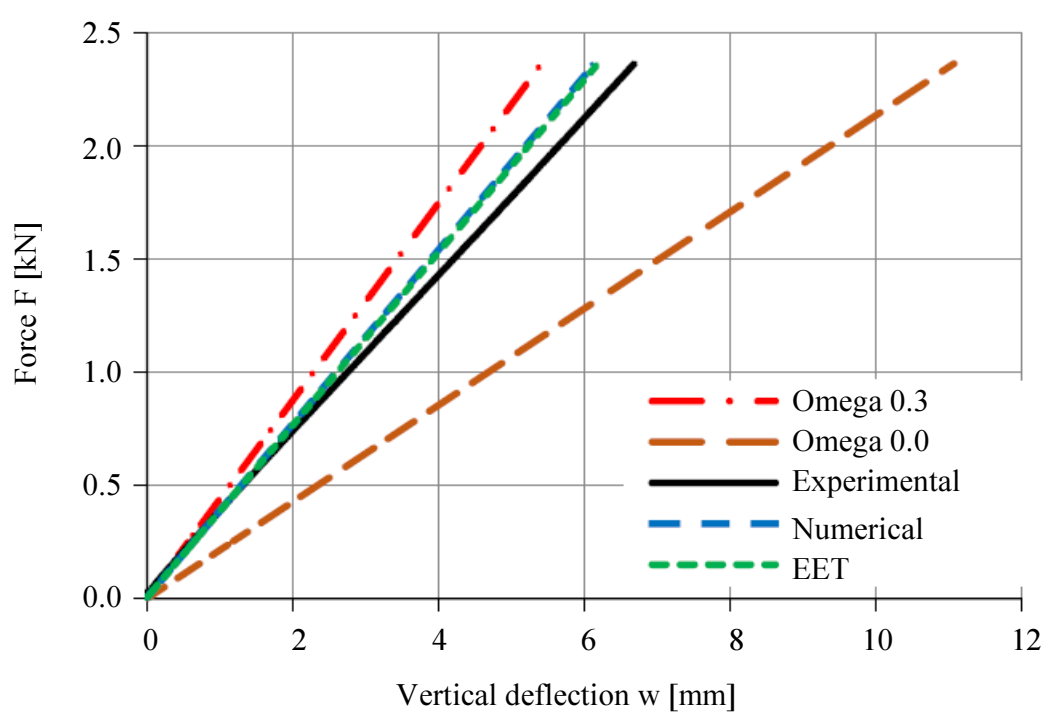

Fig. 15: Force-Deflection relations for various prediction methods, test specimen FG-PVB-07

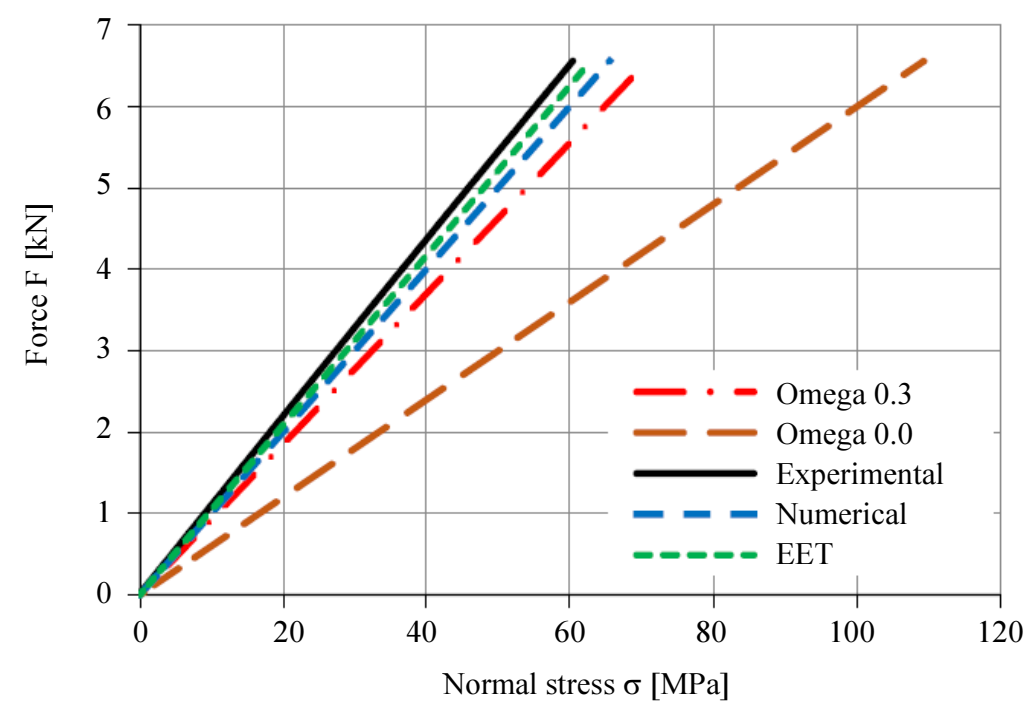

Fig. 16: Force-Stress relations for various prediction methods, test specimen FG-EVA-02

Table 7: Normal stress, average deflection and bending stiffness values for a force of $6 \mathrm{kN}$, specimen FG-EVA-02

\begin{tabular}{llll}
\hline Method & Stress (SG1) Mpa & Deflection $\mathrm{mm}$ & Stiffness $\mathrm{kN} / \mathrm{mm}$ \\
\hline Experiment & 55.2 & 10.0 & 0.60 \\
prEN16612 $(\omega=0)$ & 100.0 & 28.1 & 0.21 \\
prEN 16612 $(\omega=0.3)$ & 64.8 & 13.8 & 0.44 \\
Numerical results & 60.0 & 10.8 & 0.56 \\
EET & 57.5 & 10.7 & 0.56 \\
\hline
\end{tabular}

Figure 16 and 17 present a comparison between the experimental data and the results obtained by (prEN 16612,2013 ) and by simplified approaches for test specimen FG-EVA-02. The behaviour is similar to the behaviour in the case of ESG specimens laminated with an EVA interlayer. The shear forces transfer coefficient $\omega$ is again considered as 0.0 and 0.3 . The experimental data show that this consideration is not relevant, since the measured stress values and deflection values are more favourable. Neglecting the shear coupling of the glass plies would give conservative results, so it is desirable to use simplified calculation methods to introduce the shear coupling effect more accurately. The EET approach and the numerical calculation results are almost identical and fit well with the experimental data. Table 7 shows these results in detail for an acting force 
of $6 \mathrm{kN}$, in order to provide a brief comparison of the normal stress, the average deflection and the bending stiffness for FG-EVA-02. The highest value of normal stress 100.0 $\mathrm{MPa}$ would be obtained if one calculated according to prEN 16612 with $\omega=0$. This is too far from the experimental value 55.2 $\mathrm{MPa}$. The numerical value of normal stress $60.0 \mathrm{MPa}$ or the analytical EET value of normal stress $57.5 \mathrm{MPa}$ correlate well with the experiment. In task of deflections, the obtained results would be in a similar manner. The relations of other FGEVA test specimens were similar to the relations for specimen FG-EVA-02.

Table 8 compares the average analytical, numerical and experimental bending stiffnesses obtained for all examined specimens. The experimental values show that the panels with an EVA interlayer provided a stiffer response to the applied load, resulting in more favourable deflections than panels with PVB interlayer. The average experimental bending stiffness of the EVA panels was higher than the calculated value. In the case of PVB panels, $\omega=0.3$ would give the stiffest response.

\section{A Comparison of Experimental Data and Analytical Data - 2nd Loading Phase}

Figure 18 compares the experimentally-measured forcestress relations of the specimens for the most compressed strain gauge in the cross section with the analytical calculation according to the Navier hypothesis in the second loading phase, i.e. the entire applied load is carried by the upper glass pane because the lower pane is broken. In the analytical calculation the bending stiffness of the cross section is therefore considered only for the upper glass ply. The slopes of all experimental curves are the same, with the exception of specimen FG-PVB07, which has a noticeably higher slope. The experimental relationships show linear courses even for relatively high normal stresses. The analytical calculation provides a less favorable forcestress relation than the measured values. This may be because the interlayer with the attached shards actually provides the increase in bending stiffness. Lower surface of the upper glass ply is in the post-breakage phase in tension. Since the interlayer is not delaminated, tension stiffening of the interlayer due to the adhesion with the glass shards contributes to the cross section bending stiffness increase (Galuppi and Royer-Carfagni, 2016). To illustrate, the difference between analytical and experimental compressive normal stress for the residual force $5 \mathrm{kN}$ in case of ESG-EVA-04 specimen was $22 \mathrm{MPa}$. Table 9 shows the average values and the standard deviations of the residual loadbearing capacities for all tested specimens in the event of the collapse of the entire laminated panel (end of the 2nd loading phase) for different types of glass. Heatstrengthened glass attained the highest value of average residual loadbearing capacity $6.3 \mathrm{kN}$. In case of annealed float glass, this value was only $1.9 \mathrm{kN}$. These values prove the influence of heat treatment on the residual loadbearing capacity of heat-modified glass.

The effects of chemical treatment on the bending strength of laminated glass can be found in (Vedrtnam, 2018).

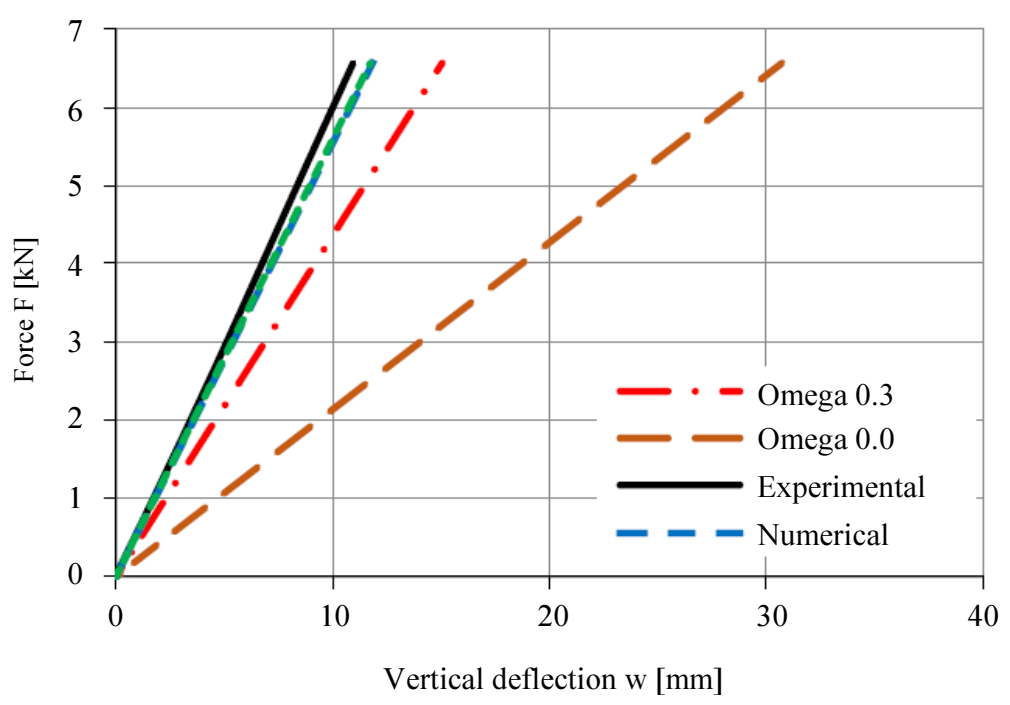

Fig. 17: Force-Deflection relations for various prediction methods, test specimen FG-EVA-02

Table 8: Comparison of EVA and PVB average bending stiffnesses for each approach

\begin{tabular}{|c|c|c|c|c|c|}
\hline Interlayer & $\begin{array}{l}\mathrm{k}_{\mathrm{EXP}} \\
\mathrm{kN} / \mathrm{mm}\end{array}$ & $\begin{array}{l}\mathrm{k}_{(\omega=0)} \\
\mathrm{kN} / \mathrm{mm}\end{array}$ & $\begin{array}{l}\mathrm{k}_{(\omega=0,3)} \\
\mathrm{kN} / \mathrm{mm}\end{array}$ & $\begin{array}{l}\mathrm{k}_{\mathrm{NUM}} \\
\mathrm{kN} / \mathrm{mm}\end{array}$ & $\begin{array}{l}\mathrm{k}_{\mathrm{EET}} \\
\mathrm{kN} / \mathrm{mm}\end{array}$ \\
\hline EVA & 0.58 & 0.21 & 0.44 & 0.56 & 0.56 \\
\hline PVB & 0.35 & 0.21 & 0.44 & 0.38 & 0.38 \\
\hline
\end{tabular}


Tomáš Hána et al. / International Journal of Structural Glass and Advanced Materials Research 2018, Volume 2: 164.177 DOI: 10.3844/sgamrsp.2018.164.177

Table 9: Average values and standard deviations of residual load bearing capacities in the event of the panel collapse Type of glass

ESG Fmean $[\mathrm{kN}]$

TVG

6.3
3.8

1.9

$\sqrt{ } \operatorname{Var}(\mathrm{F})$

FG

0.41

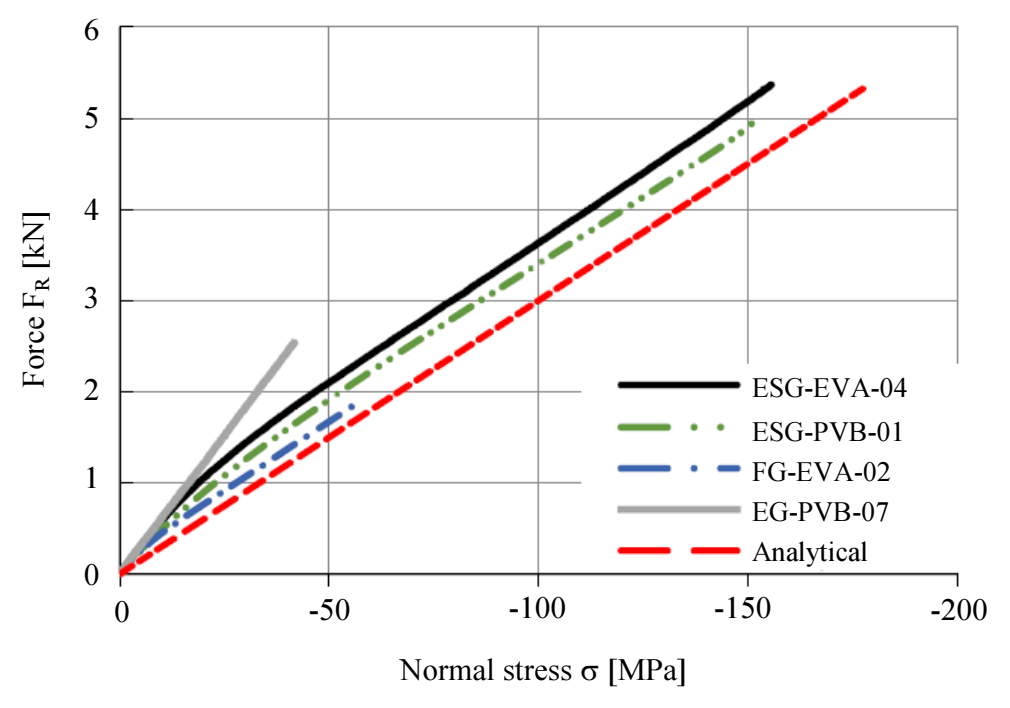

Fig. 18: Residual Force-Stress relations for representative specimens, 2nd loading phase

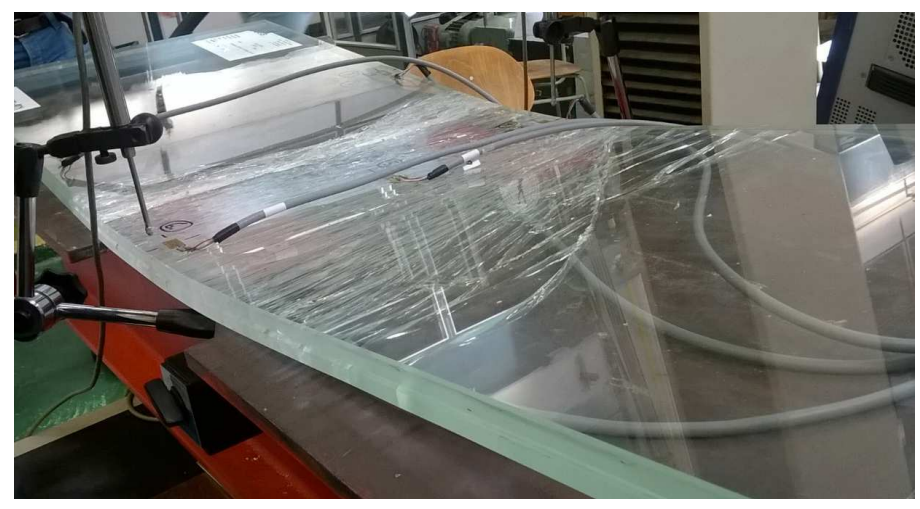

Fig. 19: Typical annealed float glass failure mode

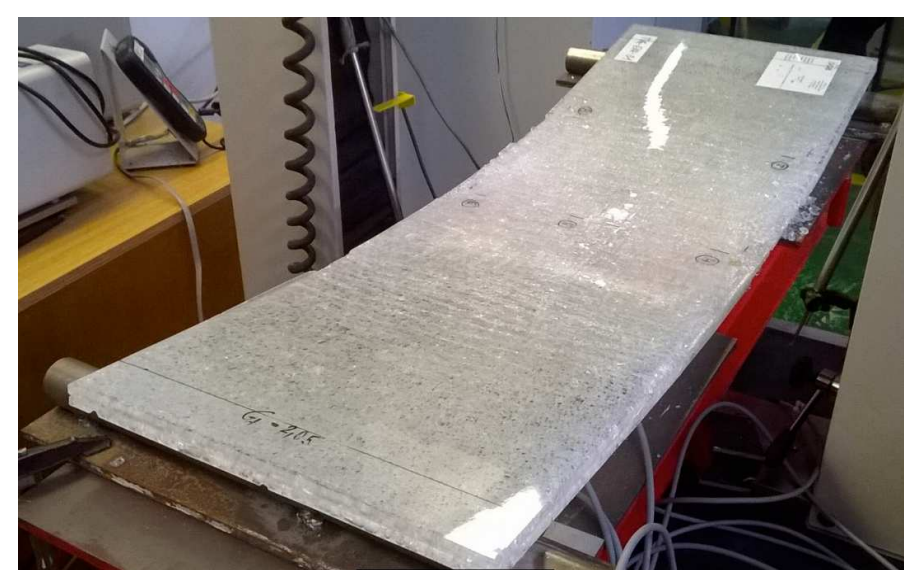

Fig. 20: Typical thermally-toughened glass failure mode 


\section{Failure Mode of the Test Specimen}

When the tensile strength of the glass was exceeded, the whole laminated panel collapsed abruptly. Shards of various shapes remained attached to the interlayer. The annealed float glass shards were much bigger and sharper than the thermally-toughened glass shards. The failure mode of panels of different types of glass was also varied. When the limit of the tensile strength of annealed float glass was reached, the core of the breakage of the panel

\section{Conclunsion}

This paper has presented important experimental results concerning a four-point bending test of EVA and PVB double laminated glass panels, performed at CTU in Prague. It has also presented a comparison between the experimental results and numerical and simplified analytical approaches, such as the EET method and the European draft (prEN 16612, 2013). Conclusions based on this research are valid only for the temperatures tested here, i.e. $+20^{\circ} \mathrm{C}$ to $+23^{\circ} \mathrm{C}$ and they can be expressed accordingly:

- The measured normal tensile stresses at the edge of the lower glass ply were higher than the normal compression stresses at the edge of the upper glass ply for panels laminated with a PVB interlayer. For panels with EVA, the differences were almost negligible

- The shear stiffness modulus values for EVA and PVB according to (Hána et al., 2017), which were used as an input for EET and for the numerical calculations, showed sufficient accuracy. These results fit well with the experimental data. For the critical normal stress measured at the moment when the lower glass ply breaks, the ratios of the numerical and experimental values were up to $9 \%$ and the ratios of EET and the experimental values they were up to $10 \%$. When comparing the deflections, the ratios of the numerical and experimental values were up to $13 \%$ and the ratios of EET and the experimental values were upto $12 \%$

- The experimental data show that panels laminated with an EVA interlayer achieve higher bending stiffness, resulting in lower tensile stresses and deflections for a certain load than panels laminated with PVB

- The enhanced effective thickness approach (EET) delivered sufficiently accurate results. However, the results were not always on the safe side. Numerical results based on experimentally-measured interlayer shear stiffness almost coincide with the results obtained by EET. At the moment when the lower glass ply broke, the critical normal stress ratios of the numerical method and the EET method calculated from all specimens were up to $4 \%$. When comparing deflections, the ratios of these methods were up to $2 \%$ was located mostly in the middle of its span, see Fig. 19. In the case of thermally-toughened glass, the situation was completely different. The panel was damaged throughout its area, providing no additional bending stiffness as Fig. 20 indicates. This is typical damage of thermally modified glass panels and is referred to as the "blanket effect". This is an unfavourable property of thermally toughened glass, since it may endanger other users of the structure.

- The measured force-stress and force-deflection relationships are linear, even for relatively high force values.

- Panels of the same glass type laminated with EVA interlayer achieved a higher ultimate load in average than panels laminated with PVB at the end of the 1st loading phase. The differences in the ultimate limit loads were more pronounced in the case of thermally-modified glass

- The analytically-calculated force-stress dependence generally delivers conservative results in the second loading phase, since it cannot include the contribution of the interlayer and the shards

\section{Acknowledgement}

This research was supported by project GA 1614770S of the Czech Science Foundation.

\section{Ethic}

The authors declare that there are no conflicts of interest.

\section{References}

ČSN EN 1288-1, 2001. Glass in a civil engineeringDetermination of the glass strength in bending, Part 1: Principles of glass testing. Czech Institute for Normalization, Prague.

ČSN EN 1288-3, 2001. Glass in a civil engineeringDetermination of the glass strength in bending, Part 3: Test of the two-points supported specimen. Czech Institute for Normalization, Prague.

DIN 18008-1, 2011. Glass in a civil engineering-Desing and Construction rules, Part 1: Conditions and general principles. German Institute for Normalization, Berlin.

Galuppi, L. and G. Royer-Carfagni, 2012. Effective thickness of laminated glass beams: New expression via a variational approach. Engineering Structures, Elsevier Ltd.

Galuppi, L. and G. Royer-Carfagni, 2013. The effective thickness of laminated glass: Inconsistency of the formulation in a proposal of EN-standards, Composites: Part B, Elsevier Ltd. 
Galuppi, L. and G. Royer-Carfagni, 2014. Enhanced Effective Thickness of multi-layered laminated glass, Composites: Part B, Elsevier Ltd.

Galuppi, L. and G. Royer-Carfagni, 2016. A homogenized model for the post-breakage tensile behavior of laminated glass, Composite Structures, Elsevier Ltd.

Galuppi, L., G. Manara and G. Royer Carfagni, 2012. Practical expressions for the design of laminated glass, Composites: Part B, Elsevier Ltd.

Hána, T., M. Eliášová, K. Machalická and M. Vokáč, 2017. Determination of PVB interlayer's shear modulus and its effect on normal stress distribution in laminated glass panels, IOP Conf. Ser.: Mater. Sci. Eng.

Molnár, G., L.G. Vigh, G. Stocker and L. Dunai, 2012. Finite element analysis of laminated structural glass plates with polyvinylbutyral (PVB) interlayer, R Periodica Polytechnica.
O'Regan C., 2014. Structural use of Glass in Buildings, 2nd Edn., IStructE Ltd, ISBN 978-1-906335-25-0

PrEN 16612, 2013. Glass in building - Determination of the load resistance of glass panes by calculation and testing, CEN

PrEN 16613, 2013. Laminated glass and laminated safety glass-Determination of interlayer mechanical properties, CEN.

Serafinavičius, T., J. Lebet, C. Louter, T. Lenkimas and A. Kuranovas, 2013. Long-term laminated glass four-point bending test with PVB, EVA and SG interlayers at different temperatures. Procedia Engineering, 57: 996-1004.

DOI: $10.1016 /$ j.proeng.2013.04.126

Vedrtnam, A., 2018. Effect of novel thermo-chemical treatment on bending strength of laminated glass. Int. J. Structural Glass Advanced Materials Research. 